\title{
An approximate procedure for estimating seismic demands for buildings
}

\author{
Benazouz Chikh ${ }^{1, *}$, Moussa Leblouba ${ }^{2}$, Youcef Mehani ${ }^{1}$ and Mohamed Hadid $^{3}$ \\ ${ }^{1}$ National Earthquake Engineering Research Center, Earthquake Engineering Division, 16005 Hussein \\ Dey Algiers, Algeria \\ ${ }^{2}$ Department of Civil \& Environmental Engineering, College of Engineering, University of Sharjah, \\ P.O. Box 27272 Sharjah, United Arab Emirates \\ ${ }^{3}$ National School of Built and Ground Works Engineering, Kouba, Algiers, Algeria
}

\begin{abstract}
Methods of the estimation of the seismic demands of nonlinear structures require a sort of iterative procedures, no matter the elastic or inelastic response spectra are used in the procedure. Many studies dealt with the development of different inelastic spectra with the aim to simplify the evaluation of inelastic deformations and performance of structures. Recently, the concept of inelastic spectra has been adopted in the global scheme of the performance-based seismic design through capacityspectrum methods (CSM).For instance, the modal pushover analysis (MPA) has been proved to provide accurate results for inelastic buildings to a similar degree of accuracy to the response spectrum analysis (RSA) in estimating peak response for elastic buildings. In this paper, a simplified nonlinear spectral analysis is made to the original MPA is proposed. The proposed procedure, which is applicable to multi-degree-of-freedom MDOF systems uses an inelastic spectrum and gives peak responses consistent with those obtained when using the nonlinear time history analysis (NL-RHA).The accuracy of the proposed procedure is verified against the nonlinear time history analysis results of two buildings. The comparison showed that the new method is capable to provide accurate peak response.
\end{abstract}

\section{Introduction}

As an alternative to the complex nonlinear dynamic analysis to estimate the seismic demands of structures, several simple evaluation methods have been proposed (Gulkan and Sozen 1974; Freeman 1975; Newmark and Hall 1982; Fajfar and Fischinger 1988; Kowalsky 1994; Sasaki et al. 1998; Gupta and Kunnath 2000; Albanesi et al. 2000; Priestley and Kowalsky 2000; Miranda 2001; Chopra and Goel 2001; Lin and Chang 2003; Maja and Fajfar 2012; Benazouz et al. 2012). Such methods are based on the characterization of the structural capacity and the good quantification of seismic intensity,

${ }^{*}$ Corresponding author: cheikhpbsd@gmail.com 
such as the Capacity Spectrum Method CSM (Freeman 1975) and its different implementations.

Since the development of the CSM Method, many response spectra have been proposed to replace the conventional elastic spectra in order to achieve accurate evaluation of the inelastic response of structures, (Sheng and Biggs 1980; Iwan 1980; Newmark and Hall 1982; Kowalsky 1994). Fajfar (1999) have proposed a N2 method for nonlinear analysis of seismic damage of reinforced concrete buildings. This method employs an inelastic response spectrum and the capacity curve is obtained from a single-degree-of-freedomsystem (SDOF) equivalent to the multi-degree-of-freedom-system (MDOF). It is implemented in Eurocode 8 (CEN 2005) and it was used in a comparison between traditional non-linear static methods in the evaluation of asymmetric structures.

The Modal Pushover Analysis (MPA), developed by Chopra and Goel (2001), which includes the effects of higher modes of vibration, provides a good estimation of the seismic demand while maintaining a simplistic concept and computing attraction due to the invariability of the distribution of forces. After, the modal pushover analysis undergoes changes by Chopra et al (2004), for which an extension of this analysis was developed under the name (Modified Modal Pushover Analysis, MMPA) that combines the elastic influence of higher modes with inelastic response of the first mode using several combinations such as the Square Roof of the Sum of Squares (SRSS).

In this paper, we first present the development of a new method based on ductility demand response spectrum (Benazouz et al., 2012) for the evaluation of seismic demands of MDOF systems. This procedure, is developed to consider the contributions of higher modes of vibration, is detailed below in this paper.

\section{Modal pushover analysis procedure (MPA)}

The modal Pushover analysis (Chopra and Goel, 2001), is based on structural dynamics theory, its accuracy and reliability in estimating the peak response of inelastic MDOF systems has been evaluated extensively by its authors. For convenience we summarize the MPA as a series of steps used to estimate the peak inelastic response of MDOF (Chopra 2007):

1. Compute the natural frequencies, $\omega_{n}$ and modes, $\phi_{n}$, for linearly elastic vibration of the building.

2. For the nth-mode, develop the base shear-roof displacement, $V_{b n}-u_{r n}$, pushover curve for force distribution

$$
s_{n}^{*}=m \phi_{n}
$$

Where $m$ is the mass matrix of the structure.

3. Idealize the pushover curve as a bilinear curve (Fig. 1a). If the pushover curve exhibits negative post-yielding stiffness, idealize the pushover curve as elasticperfectly-plastic.

4. Convert the idealized pushover curve to the force-displacement, (Fig. 1b) for the $\mathrm{n}^{\text {th }}$-mode inelastic SDOF system by utilizing

$$
\frac{\mathrm{F}_{\text {sny }}}{\mathrm{L}_{\mathrm{n}}}=\frac{\mathrm{V}_{\mathrm{bny}}}{\mathrm{M}_{\mathrm{n}}^{*}} \quad \mathrm{D}_{\mathrm{ny}}=\frac{\mathrm{u}_{\mathrm{rny}}}{\Gamma_{\mathrm{n}} \phi_{\mathrm{rn}}}
$$

In which $M_{n}^{*}$ is the effective modal mass, $F_{s n}$ is the lateral forces, $\phi_{r n}$ is the value of $\phi_{n}$ at the roof, $\Gamma_{n}=\phi_{n}^{T} m 1 / \phi_{n}^{T} m \phi_{n}$ and $L_{n}=\phi_{n}^{T} m 1$ 
5. Compute peak deformation $D_{n}$ of the $\mathrm{n}^{\text {th }}$-mode inelastic SDOF system defined by the force-deformation relation of Fig. $1 \mathrm{~b}$ and damping ratio $\xi_{n}$. The elastic vibration period of the system is

$$
T_{n}=2 \pi\left(\frac{L_{n} D_{n y}}{F_{\text {sny }}}\right)^{1 / 2}
$$

6. For an SDOF system with known $T_{n}$ and $\xi_{n}, D_{n}$ canbe computed by nonlinear response history analysis (NL-RHA) or from the inelastic design spectrum (Chopra 2007, Section 7.11).

7. Calculate peak roof displacement $u_{r n}$ associated with the nth-mode inelastic SDOF system from

$$
u_{r n}=\Gamma_{n} \phi_{r n} D_{n}
$$

8. From the pushover database (Step 2), extract values of desired responses $r_{n}$ : floor displacements, storydrifts, plastic hinge rotations, etc.

9. Repeat Steps 3-7 for as many modes as required for sufficient accuracy. Typically, the first two or three modes will suffice.

10. Determine the total response (demand) by combining the peak "modal" responses using the SRSS rule:

$$
r=\left(\sum r_{n}^{2}\right)^{1 / 2}
$$
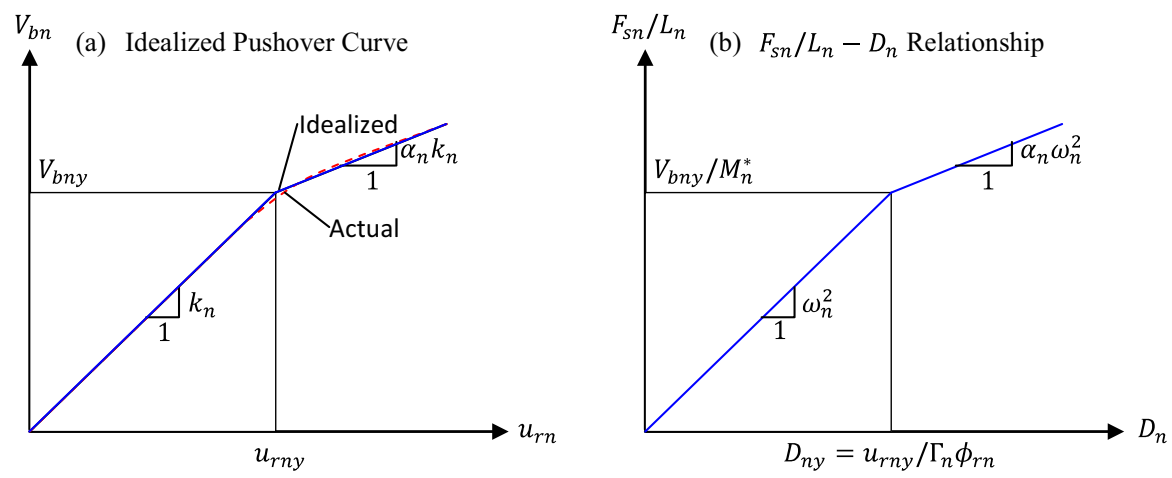

Fig.1. Properties of the nth-mode inelastic SDOF system from the pushover curve (Chopra and Goel 2001).

\section{Proposed procedure}

A simplified method is proposed for estimating the seismic response of MDOF systems. However, instead of using inelastic design spectra we use the ductility demand response spectrum (Benazouz et al., 2012). Summary of the implementation of this procedure is presented next.

The construction of the capacity curve starts with obtaining the multimodal pushover curves of the MDOF system subjected to lateral forces distributed over the building height according to $S_{n}^{*}$, where the movements will be decomposed in the form of a series of normal modes. The application of the force vector $F$ over the height of the building for each time step $t$ gives forces and stresses on the elements in a static analysis. This force distribution, $F$, can be obtained with a decomposition of the system inertia (Chopra 2007): 


$$
\mathrm{M} 1=\sum_{\mathrm{n}} \Gamma_{\mathrm{n}} \mathrm{M} \phi_{\mathrm{n}}=\sum_{\mathrm{n}} \mathrm{S}_{\mathrm{n}}
$$

Mainly the mode shapes control the capacity curve obtained using above force distribution. The capacity curve undergoes a bilinear representation as illustrated in Figure 2(a). Then, using Eq. 2 we transform the curve into AD format (Figure 2b). The obtained curve is known as the capacity diagram of the structure.
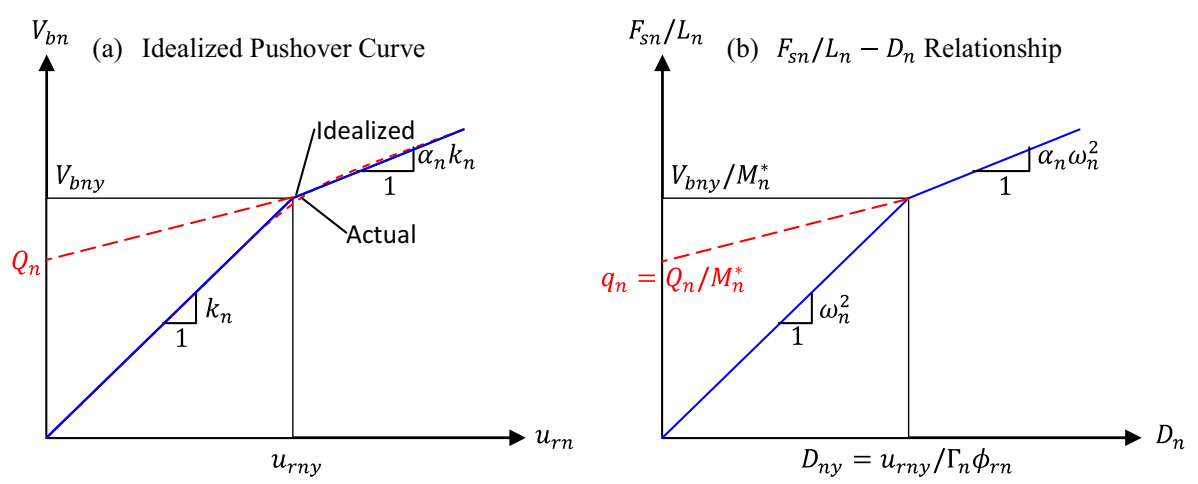

Fig.2. Properties of the $\mathrm{n}^{\text {th }}$-mode inelastic SDOF system from the pushover curve with yield strength coefficient.

For the $\mathrm{n}^{\text {th }}$ - mode, this idealization is used to calculate the yield strength $Q_{n}$ and the yield strength coefficient $q_{n}$ (Fig 2b) as follows:

$$
\mathrm{q}_{\mathrm{n}}=\frac{\mathrm{Q}_{\mathrm{n}}}{\mathrm{M}_{\mathrm{n}}^{*}}
$$

In which $\mathrm{M}_{\mathrm{n}}^{*}$ is the effective modal mass.

This coefficient will be used for evaluating the seismic demands that are represented by an inelastic response spectrum that is summarized in the next part.

The seismic demand in this paper is determined by using the Ductility-Demand Response Spectrum (DDRS) (Benazouz et al., 2012), which will be introduced in detail hereafter. In constructing the response spectra we consider an inelastic SDOF system as shown in Fig.3, its motion when subjected to an earthquake ground motion is governed by the following equation:

$$
m \ddot{x}+c \dot{x}+f(x, \dot{x})=-m \ddot{x}_{g}(t)
$$

Where $\mathrm{m}, \mathrm{c}$, and $\mathrm{f}$ represent the mass, damping, and the resisting force of the system, respectively. $\ddot{x}_{\mathrm{g}}(\mathrm{t})$ denotes the earthquake acceleration input to the SDOF.

The resisting force $\mathrm{f}$ is defined as the sum of the linear part and the hysteretic part:

$$
\mathrm{f}=\mathrm{k}_{\mathrm{p}} \mathrm{x}+\mathrm{Qz}
$$

In the above equation, $\mathrm{k}_{\mathrm{p}}$ is the postyield stiffness, $\mathrm{Q}$ is the yield strength (it has been determined through the capacity curve), and $\mathrm{z}$ represents the dimensionless variable that characterizes the Bouc-Wen model of hysteresis (Wen 1976), it is given by:

$$
\dot{\mathrm{z}}=\frac{\dot{\mathrm{x}}}{\mathrm{x}_{\mathrm{y}}}\left[\mathrm{A}-|\mathrm{z}|^{\lambda}(\operatorname{Bsign}(\dot{\mathrm{x}} \mathrm{z})+\beta)\right]
$$




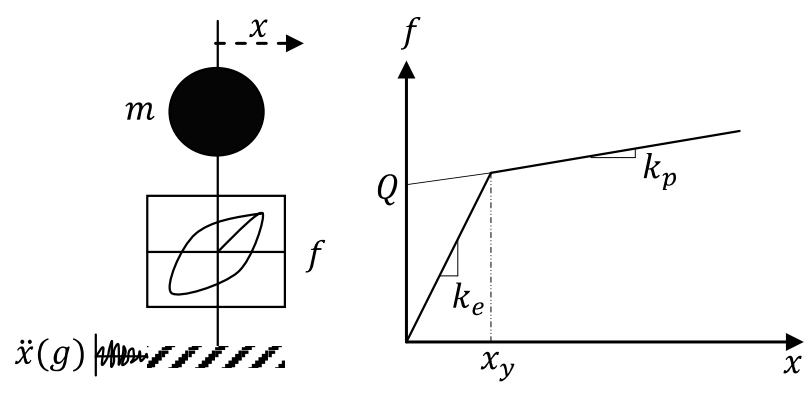

Fig. 3. Capacity curve of a (SDOF) bilinear system.

In Eq. (10), $x_{y}$ is the yield displacement; $A, B, \lambda$, and $\beta$ are the parameters that control the shape of the hysteresis loop.

Substituting Eq. (9) into Eq. (8) and dividing by m yields:

$$
\ddot{\mathrm{x}}+2 \xi \omega \dot{\mathrm{x}}+\alpha \omega^{2} \mathrm{x}+\mathrm{qgz}=-\ddot{\mathrm{x}}_{\mathrm{g}}(\mathrm{t})
$$

In which: $\xi, \omega, \alpha$, and $q$ represent the damping ratio, circular frequency, post-to-preyield stiffness ratio, and the yield strength coefficient, respectively. From Fig $2 \mathrm{~b}, \mathrm{q}$ is defined as the yield strength divided by the system weight $w, w=m g$ where $g$ stands for the gravity, respectively.

Next, Eq. (11) is rewritten in terms of ductility factor, $\mu$. Substituting: $x=x_{y} \mu, \dot{\mathrm{x}}=\mathrm{x}_{\mathrm{y}} \dot{\mu}$, and $\ddot{x}=x_{y} \ddot{\mu}$ in Eq. (11) and dividing by $x_{y}$ gives:

$$
\ddot{\mu}+2 \xi \omega \dot{\mu}+\alpha \omega^{2} \mu+\omega^{2}(1-\alpha) z=-\frac{\omega^{2}(1-\alpha)}{\mathrm{qg}} \ddot{x}_{\mathrm{g}}(\mathrm{t})
$$

It can be observed from Eq. (12) that for a given ground acceleration, $\mu(t)$ depends on $\xi, \omega, \alpha$ and $q$. To obtain meaningful system response to an ensemble of ground motions, the system yield strength coefficient has to be defined relative to the intensity of individual ground motions. Using the parameter $\eta$ introduced by Mahin and Lin (1983) as:

$$
\eta=\frac{q g}{P G A}
$$

where, PGA stands for the Peak Ground Acceleration.

Incorporating $\eta$ into Eq. (12) results:

$$
\ddot{\mu}+2 \xi \omega \dot{\mu}+\alpha \omega^{2} \mu+\omega^{2}(1-\alpha) z=-\frac{\omega^{2}(1-\alpha)}{\eta} \overline{\mathrm{x}}_{\mathrm{g}}(\mathrm{t})
$$

In which, $\overline{\mathrm{x}}_{\mathrm{g}}(\mathrm{t})$ represents the ground acceleration normalized with respect to the PGA.

The procedure to construct the ductility demand response spectrum for inelastic systems corresponding to specified levels of normalized yield strength $\eta$, is summarized in the following steps (Benazouz et al., 2012) :

1. Define the ground motion $\ddot{x}_{g}(t)$;

2. Select and fix the damping ratio $\xi$ and the post-to-preyield stiffness ratio $\alpha$.

3. Specify a value for $\eta$;

4. Select a value for elastic period $T$;

5. Determine the ductility response $\mu(t)$ of the system with, $T, \xi$ and $\alpha$ equal to the values selected by solving Eq. (14). From $\mu(t)$ determine the peak ductility factor $\mu$ 
6. Repeat steps 4-5 for a range of $T$, resulting in the spectrum values for the $\eta$ value specified in step 3 .

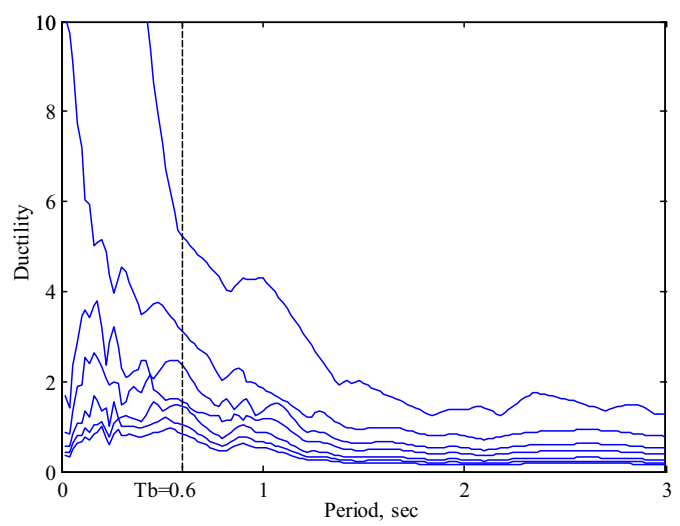

Fig. 4. DDRS for inelastic system computed for El Centro 1940 (N/S) component $(\alpha=10 \%, \xi=$ $5 \% \eta=0.25,0.5,0.75,1,1.5,2,2.5$ from top line to bottom line).

The value of the ductility factor is read from the spectrum developed by the above procedure and multiplied by $\mathrm{x}_{\mathrm{y}}$ to obtain the peak deformation $\mathrm{x}_{\mathrm{m}}$.

The spectrum was divided logically into three period regions according to the last work described in (Benazouz et al., 2012). In Fig. 4, $\mathrm{T}_{\mathrm{b}}$ marks the transition from the acceleration-sensitive region to the velocity-sensitive region which ends around $\mathrm{T}=3 \mathrm{sec}$. For the nth-mode, the maximum displacement of the original structure based on ductility is given by:

$$
\mathrm{x}_{\mathrm{n}}=\mu \mathrm{x}_{\mathrm{y}}
$$

This is determined from the ductility demand response spectrum (DDRS). At this level, the pushover analysis provides a good estimation of the maxima $r_{n o}$ (peak modal response) of any response (displacement profile, story drifts, joint rotations, etc.)

Combining those modal responses using any of the proved modal combination methods (Eq. 5) we obtain a good estimation of the peak value $r_{o}$ of the total structural response.This technique lacks theoretical basis, however it is proved to provide meaningful results.

\section{Application and discussion}

Two examples of eight and three stories reinforced concrete plane frame structures (regular structures) are considered in order to evaluate the efficiency of the proposed method. They have been chosen for representing the behavior of low and medium-rise buildings. These examples are an eight $(8 \mathrm{St})$ and three-story $(3 \mathrm{St})$ reinforced concrete buildings as illustrated in Fig. 5. These structures are designed according to the Algerian code RPA-2003 (CGS 2003). Each structure consists of three bays frame, spaced at $4 \mathrm{~m}$ and a uniform story height of $3 \mathrm{~m}$ with no significant height irregularities. The purpose of this study is to confirm the application of the proposed method for each frame structure under a design earthquake. The geometric properties of the components are presented in Fig. 5. Vibration modes and periods of these structures for linearly elastic case are summarized in Table 1 . The capacity curves were obtained by applying the Adaptive Pushover Analysis (Reinhorn et al. 2006). 
These curves were transformed to the capacity diagram $\left(S_{a n}-D_{n}\right)$ format, and gave the curves shown in Fig. 6. The numerical models were simulated using IDARC program (Reinhorn 1997). The supports were modeled as infinitely rigid to avoid the soil-structure interaction. The periods of the selected structures were: $\mathrm{T}=0.81 \mathrm{sec}$ for the $8 \mathrm{St}$ building, in the velocity-sensitive spectral region, and $\mathrm{T}=0.32 \mathrm{sec}$ for the $3 \mathrm{St}$ building, in the acceleration-sensitive spectral region. Results obtained show that the proposed procedure give peak displacements close to those that obtained by NL-THA. Concrete compressive strength was $25 \mathrm{MPa}$. Concrete density is $2.5 \mathrm{t} / \mathrm{m}^{3}$, concrete Young modulus is $3.2110^{7}$ $\mathrm{kN} / \mathrm{m}^{2}$ and reinforcements yield strength is $400 \mathrm{MPa}$.

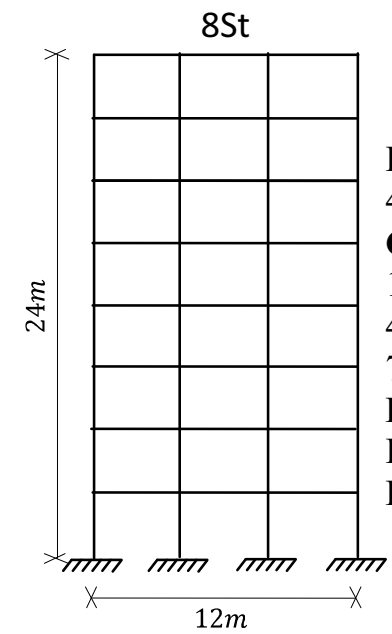

\section{Beams}

$40 * 35 \mathrm{~cm}^{2}$

\section{Columns}

$1^{\text {st }}-3^{\text {rd }}$ level $60 * 60 \mathrm{~cm}^{2}$

Beams

$4^{\text {th }}-6^{\text {th }}$ level $50 * 50 \mathrm{~cm}^{2}$

$7^{\text {th }}$ and $8^{\text {th }}$ level $40 * 40 \mathrm{~cm}^{2}$

Dimensions:

Level height $3.0 \mathrm{~m}$

Bay widths (all) $4.0 \mathrm{~m}$

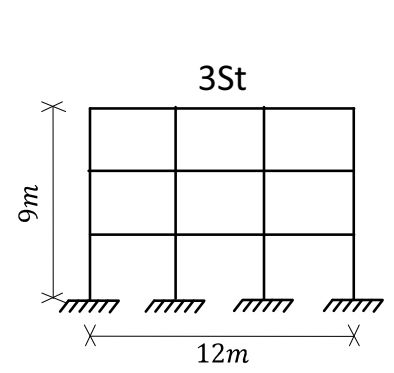

$35 * 30$

Colum

$60 * 60$

Dimen

Level 1

Bay wi

Fig. 5. Elevation view of the $8 \mathrm{St}$ and $3 \mathrm{St}$ structures.

Table 1. Dynamic characteristics

\begin{tabular}{|c|c|c|c|c|c|}
\hline & Mode & $\boldsymbol{f}_{\boldsymbol{n}}(\boldsymbol{H z})$ & $\boldsymbol{T}_{\boldsymbol{n}}(\boldsymbol{s e c})$ & $\boldsymbol{\Gamma}_{\boldsymbol{n}}$ & $\boldsymbol{L}_{\boldsymbol{n}}(\%)$ \\
\hline \multirow{3}{*}{8 St } & 1 & 1,22 & 0,81 & 1,558 & 77,10 \\
\cline { 2 - 6 } & 2 & 3,60 & 0,27 & $-0,611$ & 11,87 \\
\cline { 2 - 6 } & 3 & 6,40 & 0,15 & $-0,386$ & 4,74 \\
\hline \multirow{3}{*}{$3 \mathrm{St}$} & 1 & 3.13 & 0.32 & 0.461 & 85.63 \\
\cline { 2 - 6 } & 2 & 10.54 & 0.094 & 0.168 & 11.38 \\
\cline { 2 - 6 } & 3 & 20.07 & 0.05 & 0.086 & 2.3 \\
\hline
\end{tabular}

\subsection{Ground motion records}

Four ensembles of ground motions, each with 20 records were considered in this application. The ensembles, denoted by LMSR, LMLR, SMSR, and SMLR represent four combinations of large $(M=6.6-6.9)$ or small $(M=5.8-6.5)$ magnitude and short $(R=13-30$ $\mathrm{km})$ or long $(\mathrm{R}=30-60 \mathrm{~km})$ epicentral distance. These motions were selected from the PEER (Pacific Earthquake Engineering Research Center) Strong Motion Database. More details about this database can be found elsewhere (Chopra et al., 2003). These values were used for both horizontal directions of ground motion in the proposed procedure in order to be able to compare its results with those obtained by NL-THA. 


\subsection{Capacity curve}

First, the Pushover curves of the two structures were transformed to the equivalent SDOF system (see Fig. 6). For example the Pushover curve of the eight-story structure is transformed to the equivalent SDOF capacity curve. In this case, the transformation factor amounts of $\Gamma_{1}=1.558$, and the effective mass is equal to $\mathrm{L}_{1}=40912454.4 \mathrm{~kg}$. The capacity diagram shown in Fig. 9 was obtained by dividing the forces corresponding to the idealized SDOF system by the equivalent mass. For $8 \mathrm{St}$ structure, the yield strength ratio is equal to $\mathrm{q}_{1}=\mathrm{Q}_{1} / \mathrm{L}_{1}=0.795$.
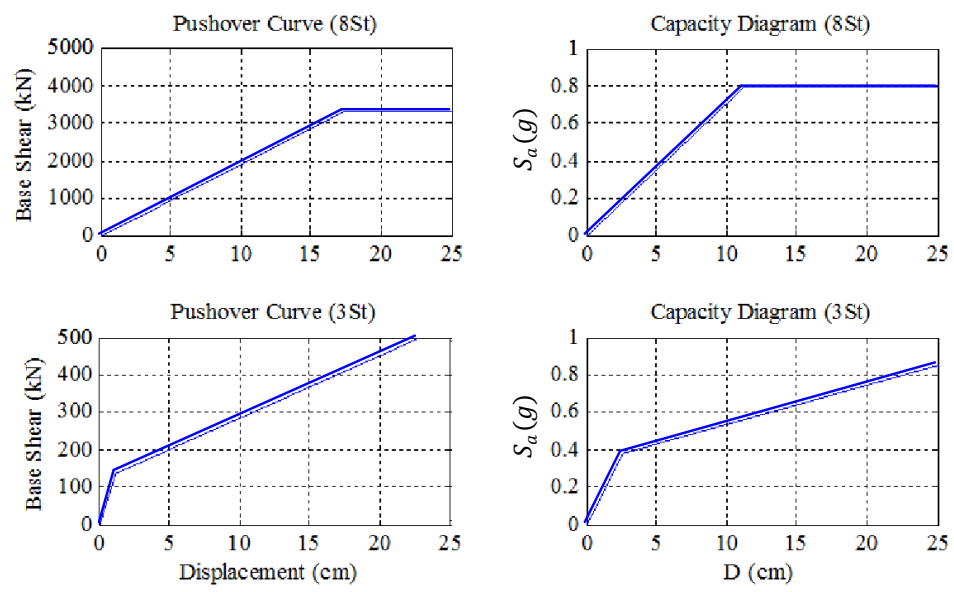

Fig. 6. Pushover curve and capacity diagram of the 1 st mode for the $8 \mathrm{St}$ and the $3 \mathrm{St}$ structures.

\subsection{Seismic demand}

The simplified procedure was evaluated by comparing the computed displacements (displacement divided by the building height), and the inter-story drift ratio (relative drift between two consecutive stories normalized by story height). Since the time-history results were based on a set of 80 simulations, both the mean and the dispersion (standard deviation $\sigma)$ about the mean value are shown in the plots.

Peak displacement profiles and inter-story drift ratio profiles estimated by the NL-THA analyses and those obtained by the proposed procedure for the buildings are shown in Figs. 7 - Fig.8. These figures show the means and the standard deviations of the peak displacement profile estimated by NL-THA analyses and the predictions using the proposed procedure for each building sorted by type of record.

The displacement demands along the heights of the buildings showed that the proposed method gives good results and generally yield to better estimates of the peak displacement profiles particularly for the $8 \mathrm{St}$ building. Comparing the time-history responses for the different accelerations indicates that the difference between the ground motion of far field records and near field records generally produce more variability in the demands. It is interesting to mention that the story displacement demands from the proposed method are always conservative. 


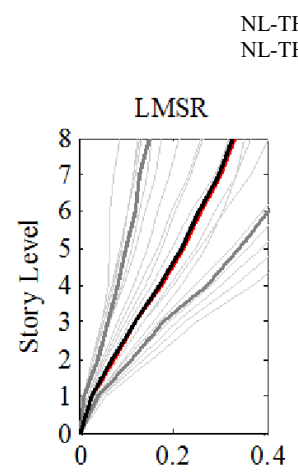

NL-THA (mean)

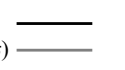

NL-THA

Proposd Procedure
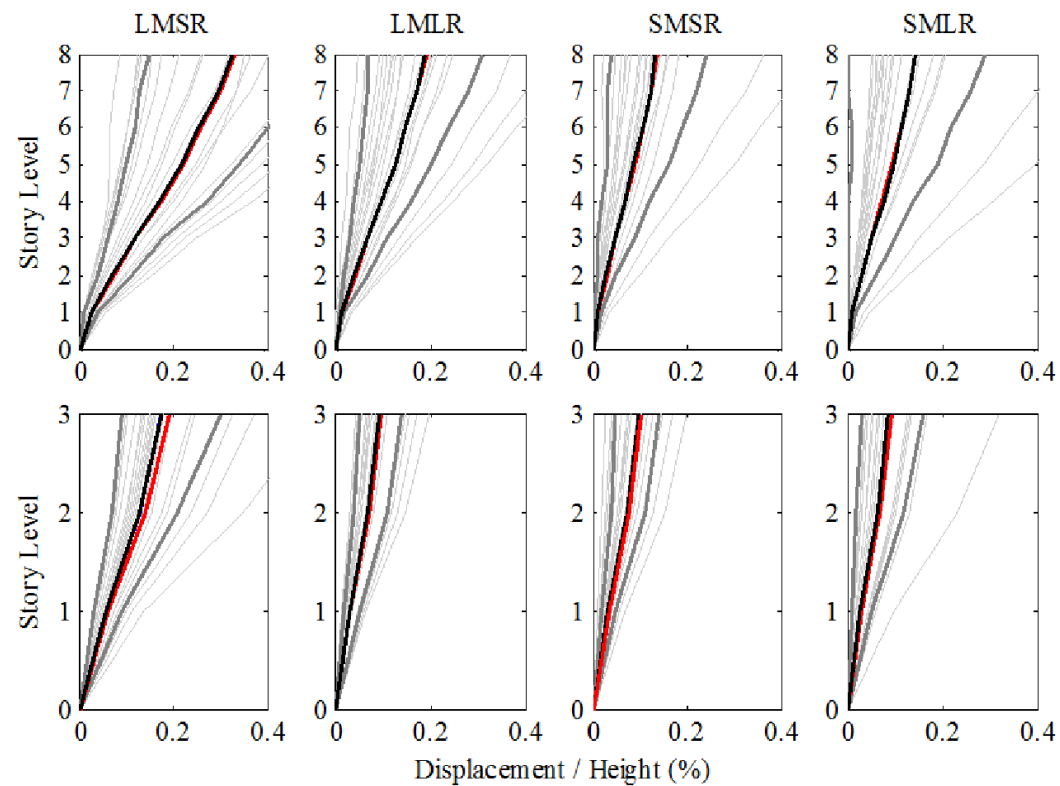

Fig. 7. Displacements obtained by the proposed procedure and NL-THA for the four ensembles.

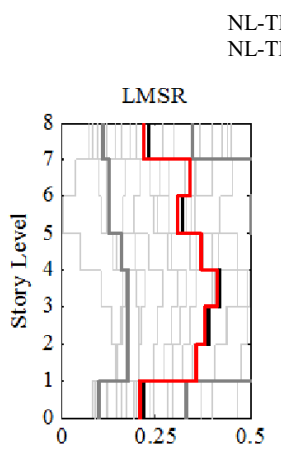

NL-THA (mean)

NL-THA

Displacement / Height (\%)

\section{.}




\section{Conclusions}

An approximate procedure for seismic demands assessment of MDOF system has been developed and its accuracy was verified by examples. An inelastic modal decomposition in terms of ductility has been developed to construct the simplified procedure. That was verified using the seismic response of an example steel frame structure for which capacity curve data is available. The results indicated that more reliable displacement predictions are obtained from the proposed method.

The base shear-roof displacement $\left(\mathrm{V}_{\mathrm{bn}}-\mathrm{x}_{\mathrm{rn}}\right)$ curve is developed from a Pushover analysis. This Pushover curve is idealized as a bilinear force-deformation relation for the nth mode of inelastic SDOF system. This idealization is used to determine the normalized yield strength coefficient $\eta_{\mathrm{n}}$ and the post-to-preyield stiffness ratio $\alpha_{\mathrm{n}}$ to estimate the ductility demand. The peak deformation of this SDOF system, determined by the design spectra DDRS, is used to determine the target value of roof displacement at which the seismic response is determined by the Pushover analysis. The total demand is determined by combining the responses of the first three modes by the SRSS combination rule.

The efficiency of the simplified procedure is evident; the designer needs only to have the Pushover curve of the structure and the design earthquake(s) to determine peak response of any structure, namely, base displacement and base shear. This method is applicable to a variety of uses such as a rapid evaluation technique for a large inventory of buildings, a design verification procedure for new construction, an evaluation procedure for an existing structure to identify damage states. The ductility demand is given by the direct estimation where the ductility calculated from the design spectra diagram matches the value associated with the period of the system.

\section{References}

1. Albanesi, T., Nuti, C. and Vanzi, I. (2000), "A simplified procedure to assess the seismic response of nonlinear structures", Earthq. Spectra, 16(4), 715-734.

2. Benazouz, C., Moussa, L. and Ali, Z, (2012), "Ductility and inelastic deformation demands of structures", J. Struct. Eng. Mech, 42(5), 631-644.

3. CEN (2005) Eurocode 8 - design of structures for earthquake resistance. Part 3: assessment and retrofitting of buildings. European standard EN 1998-3. June 2005. European Committee for Standardization, Brussels

4. CGS (2003), Algerian seismic building code, National Center of Applied Research in Earthquake Engineering CGS, Algiers.

5. Chikh B, Mehani Y and Leblouba M. (2016). Simplified procedure for seismic demands assessment of structures. Structural Engineering and Mechanics. 59(3):455473.

6. Chopra, A.K. and Goel, R.K. (2001), A Modal Pushover Analysis Procedure to Estimate Seismic Demands for Buildings: Theory and Preliminary Evaluation, PEER, Berkely, California, 2001/03.

7. Chopra, A.K. and Chatpan, C. (2003), Inelastic deformation ratios for design and evaluation of structures: single-degree-of-freedom bilinear systems. EERC, Berkely, California, 2003/09.

8. Chopra, A.K. and Chatpan, C. (2004), "Inelastic deformation ratios for design and evaluation of structures: single-degree-of-freedom bilinear systems", J. Struct. Eng, 130(9), 1309-1319.

9. Chopra, A.K. (2007), Dynamics of Structures - Theory and Applications to Earthquake Engineering, (3rd Edition), Prentice Hall, New Jersey. 
10. Fajfar, P. and Fischinger, M. (1988), "N2 a method for nonlinear seismic analysis of regular structures" Proceedings of 9th World Conf on Earth Eng, Tokyo-Kyoto, Japan, 5:111-116.

11. Freeman, S.A., Nicoletti, J.P. and Tyrell, J.V. (1975), "Evaluation of existing buildings for seismic risk-a case study of Puget Sound Naval Shipyard", Proceedings of 1st U S National Conference on Earthquake Engineering, Berkeley, USA, pp 113-122.

12. Iwan W D (1980) Estimating inelastic spectra from elastic spectra. Earthq Eng Struct Dyn. 8(4):375-388.

13. Gülkan, P. and Sözen, M. (1974), "Inelastic response of reinforced concrete structures to earthquake motions". ACI J Proceedings. 71(12), 604-610.

14. Gupta, B. and Kunnath, S.K. (2000), "Adaptive spectra-based pushover procedure for seismic evaluation of structures", Earthq. Spectra, 16(2), 367-392.

15. Kowalsky, M.J. (1994), "Displacement-based design-a methodology for seismic design applied to RC bridge columns", Master's thesis, University of California at San Diego, La Jolla, California.

16. Lin, Y.Y. and Chang, K.C. (2003), "An Improved Capacity Spectrum Method for ATC-40, Earthq. Eng. Struct. D, 32(13), 2013-2025.

17. Maja, K. and Fajfar, P. (2012), "The extended N2 method considering higher mode effects in both plan and elevation", Bull. Earth. Eng, 10(2), 695-715.

18. Miranda, E. (2001) "Estimation of inelastic deformation demands of SDOF systems", J. Struct. Eng., 127(9), 1005-1012.

19. Newmark, N.M. and Hall, W.J. (1982), "Earthquake spectra and design”, Earthquake Engineering Research Institute, Berkeley, California.

20. PEER Strong Motion Database [Online]. http://peer.berkeley.edu/smcat.

21. Priestley, M.J. and Kowalsky, M.J. (2000), "Direct Displacement-Based Seismic Design of Concrete Buildings", Bull of the New Zealand Society for Earth Eng, 33(4), 421-444.

22. Reinhorn, A.M. (1997), "Inelastic analysis techniques in seismic evaluations", Fajfar, P. and Krawinkler, H. (eds.), "Seismic design methodologies for the next generation of codes", Balkema, Rotterdam, pp: 277-287.

23. Reinhorn, A.M., Valles, R.E. and Kunnath, S.K. (2006), "IDARC 2D version 6.1User's Guide", State University of New York, Buffalo, NY.

24. Sasaki, K.K., Freeman, S.A. and Paret, T.F. (1998), "Multimode pushover procedure (MMP) - A method to identify the effects of higher modes in a pushover analysis", Proceeding of the 6th U.S. Nat. Conf. on Earthq. Eng, Seattle, Washington.

25. Shih-Sheng P L, John M B (1980) Inelastic response spectra for a seismic building design. ASCE J Struct Div. 106(6):1295-1310.

26. Wen, Y.K. (1976), "Method for random vibration of hysteretic systems", J. Eng. Mech., 102(2), 249-263. 